DOI: $10.17805 /$ trudy.2018.5.9

\title{
ИННОВАЦИИ И СОВРЕМЕННЫЕ ТРЕНДЫ В МЕНЕДЖМЕНТЕ ЗДРАВООХРАНЕНИЯ РЕСПУБЛИКИ КАЗАХСТАН И РОССИЙСКОЙ ФЕДЕРАЦИИ
}

\author{
А. А. Мураталиева \\ Московский гуманитарный университет
}

\begin{abstract}
Аннотация: Современные тенденции в области построения сервисного государства требуют первоочередность тех инновационных процессов развития системы менеджмента медицины, которые способствуют повышению социального эффекта и результата. В статье анализируются примеры менеджмента Казахстана и России.
\end{abstract}

Ключевые слова: система здравоохранения; менеджмент здравоохранения; Казахстан; Россия

\section{INNOVATIONS AND MODERN TRENDS IN HEALTHCARE MANAGEMENT IN THE REPUBLIC OF KAZAKHSTAN AND THE RUSSIAN FEDERATION}

\author{
A. A. Muratalieva
}

Moscow University for the Humanities

Abstract: Modern trends in the construction of a service state require the priority of the innovative processes in the development of the medicine management system which contribute to an increase in social effect and result. The paper analyses examples of management in Kazakhstan and Russia.

Keywords: healthcare system; healthcare management; Kazakhstan; Russia

Если попытаться охарактеризовать время, которое мы переживаем в последние годы, то можно, наверное, назвать его не только временем смены двух тысячелетий, но и глобального изменения общественно-политических формаций, ценностей и социальных запросов населения Земли. В мире ширится понимание общности судеб жителей нашей планеты, необходимости борьбы против терроризма, войн и особенно против ядерной угрозы человечеству. В свете тенденций последних лет, Россия и Казахстан находятся на этапе активного индустриально-инновационного и экономического развития. Безусловно, любые существенные процессы в экономике и обществе требуют привлечения колоссальных человеческих ресурсов, бережное от- 
Научные труды Московского гуманитарного университета 2018 № 5

ношение к жизни и здоровью населения, и это становится первоочередным условием достижения стратегических планов и инициатив государств.

Так, в Стратегическом плане развития Республики Казахстан до 2020 г. отмечалось, что одной из приоритетных задач являлись «инвестиции в будущее», которые предусматривают к 2020 году достичь таких результатов по управлению человеческими ресурсами, которые необходимы для модернизации и развития экономики. Государственная программа развития здравоохранения Республики Казахстан «Денсаулық»на 2016-2019 годы является комплексом конкретных мер по развитию человеческого капитала республики в области качественного улучшения показателей здоровья населения. Заметим, что нашим гражданам постсоветских республик, вообще свойственно оптимистическое мировосприятие и оптимистическая оценка собственных жизненных перспектив. Человек может приспособиться почти к любым социальным, экономическим, культурным моделям, но ценой за это может быть снижение интеллектуальных и нравственных качеств личности.

Тут, по-видимому, будет уместно отметить, что организационным и управленческим аспектам отводится главенствующая роль в обеспечении процесса повышения показателей основных индикаторов успешной реализации ныне действующей программы:

- увеличение средней прогнозируемой продолжительности жизни казахстанцев до 73 лет. Стоит отметить, что в 2017 г. данный показатель уже достиг отметки 72 года;

- повышение индекса здоровья на 20\%;

- повышение уровня удовлетворенности населения услугами здравоохранения до 46\% (Государственная программа ... , 2016: Электр. ресурс).

В числе ключевых задач достижения данных индикаторов, ведущую роль занимают аспекты совершенствования менеджмента здравоохранения, в части подготовки, селекции кадров и повышения эффективности управленческой структуры. Это дает возможность выявить степень и особенности адаптации современной медицины к новым социальным условиям, а также выявить и оценить ее инновационный потенциал. Социализация начинается еще в школе, где во многом определяет не только будущее индивида и успешность его включения в общество, но также способность к выживанию, развитию, обновлению самого общества. Необходимо также учитывать, что есть разные поколения, входящие в состав единого национально-государственного организма - это разный жизненный опыт, разные взгляды на мир, разные образы жизни, жизненные цели, стратегии, планы, убеждения, по существу - разные люди. Эти меры, позволяет проявлять здоровый социальный оптимизм в отношении будущего нашего общества. 
В Концепции долгосрочного социально-экономического развития Российской Федерации на период до 2020 года развитие человеческого потенциала также является одним из стратегически важных условий реализации социально-экономических преобразований общества. Улучшение социальной среды и качества жизни отмечается как одно из ключевых условий повышения конкурентоспособности населения в целом. В среднесрочной и долгосрочной перспективе, вопросам модернизации и совершенствования системы здравоохранения отводится первостепенная роль в улучшении качества жизни населения. В то же время, основной задачей модернизации системы здравоохранения является развитие эффективных механизмов распределения и освоения финансовых и материальных ресурсов, обеспечения соблюдения государственных и мировых стандартов в области оказания медицинских услуг населению, повышения качества работы организаций здравоохранения (Распоряжение Правительства ... , Электр. ресурс).

Эта проблема в Казахстане, как и в России, стоит не менее, а может быть, более остро, потому что ее приходится решать в условиях острого экономического кризиса. Вместе мы не должны допустить, чтобы в обществе нагнетался пессимизм, социальная безысходность. Иными словами, тенденции последних лет таковы, что подходы к развитию системы здравоохранения претерпевают значительные изменения, связанные не только с технологическим совершенствованием услуг в области охраны здоровья, но и совершенствованием организационных и управленческих механизмов. Одним из ключевых вопросов повышения качества медицинских услуг для населения является достижение бесперебойного и комфортного процесса деятельности медицинского учреждения, как для его работников, так и для населения (Добрусина, 2016). Поэтому, повышение эффективности системы здравоохранения, увеличения спектра и расширение охвата населения медицинскими услугами напрямую связано с передовыми достижениями менеджмента.

Основным отличием инновационного развития в менеджменте здравоохранения является качественное и интенсивное улучшение всех составляющих компонентов: организационной структуры, экономических механизмов, подходов к управлению кадровым потенциалом, методологических и технических основ организации руководства медицинским учреждением. Другой важной тенденцией является необходимость формирования профиля системы управления здравоохранением под запросы и ожидания общества. В конечном счете, сегодня как никогда результативность изменений в системе здравоохранения зависит от общественного одобрения и соответствия ожиданиям и потребностям населения. Поэтому, в эпицентре реформационных процессов в менеджменте здравоохранения находятся те тренды, которые характерны для медицины как общественно-значимой 
Научные труды Московского гуманитарного университета 2018 № 5

отрасли. Соответственно, и управление инновационным развитием менеджмента медицины происходит, и будет происходить в дальнейшем в рамках контролируемого государством процесса экономико-социального преобразования.

Поэтому, одним из наиболее ярких изменений последних лет является усиление социального аспекта в области менеджмента здравоохранения, что заметно проявляется в двух направлениях:

- усиления превентивных мер по усиление заболеваемости граждан;

- усиления контроля и формирование концепции развития социальной политики государства.

На сегодняшний день, в Республике Казахстан, как и в Российской Федерации, социальная политика находится в фокусе повышенного внимания. Создание социальных гарантий для граждан, в частности гарантий обеспечения достойного уровня и качества жизни в результате наступления медицинских рисков, является неотъемлемой частью государственной политики государства с высоким уровнем социально-экономического развития, к параметрам которого стремятся страны - участницы ЕАЭС.

Так, в Республике Казахстан на конституциональном уровне закреплено единообразие государственной политики и контроля в области здравоохранения (статья 114). Статья 29 регулирует права граждан Республики Казахстан на медицинскую помощь и поддержку государства случаи наступления нетрудоспособности (Конституция Республики ... , Электр. ресурс).

В Российской Федерации, законодательным основанием осуществления государственной политики является ст.7 п. 2 Конституции РФ. Статьей 41 главы 2 регулируются права на оказание медицинской помощи и реализацию социальной поддержки инвалидности (Конституция Российской ... , Электр. ресурс).

По сравнению с прошедшими десятилетиями, роль государственных инициатив и полномочий в области поддержки инвалидности как в Республике Казахстан, так и в Российской Федерации существенно усилилась. Кроме того, общество наших стран активно включено в процесс трансформации социальной среды и ее взглядов на инвалидность. Сегодня инклюзия является ведущей тенденцией преобразования социально-экономической сферы, создания условий для максимально полного вовлечения всех категорий граждан в общественные, социокультурные и экономические процессы настолько, насколько это возможно с медицинской точки зрения. В Республике Казахстан 662000 лиц с инвалидностью, в Российской Федерации - 12259000 человек (Общая численность ... , Электр. ресурс).

Данная тенденция способствует формированию особых условий функционирования менеджмента здравоохранения. В первую очередь, совре- 
менный менеджмент здравоохранения должен учитывать фактор социальной инклюзии, и те нормативные и методические требования, которые предъявляются на современном этапе к организациям здравоохранения и их функциям в реализации социальной политики государства.

В частности, создание инклюзивной социальной среды требует соответствующих условий организации рабочего, творческого и жизненного пространства граждан, для эффективной реализации государственной политики в области социальной поддержки. Например, с 2017 г. в казахстанских центрах обслуживания населения внедрены онлайн-сурдопереводчики, активно идет обустройство общественной инфраструктуры и архитектуры под потребности людей с ограниченными возможностями (Махашев, 2017: Электр. ресурс). В Российской Федерации активно формируется среда для творческой профессиональной активности людей с ограниченными возможностями. С 2016 г. действует Федеральный государственный образовательный стандарт начального общего образования обучающихся с ограниченными возможностями здоровья (Приказ Минобрнауки РФ ... , Электр. ресурс).

Несмотря на внушительные успехи, все еще имеются проблемы, указывающие на то, что темпы инклюзивных процессов могут быть и более продуктивными и более интенсивными. Так, по словам В. Алаева, исполнительного директора 00 «Кенес», статистика по проценту трудоустроенных инвалидов завышена (Муханов, 2017). В связи с этим усиливается необходимость организации менеджмента здравоохранения как открытой системы, вписанной в концепцию сервисной модели государства, активно взаимодействующей с иными государственными системами, институтами, механизмами и населением.

Формирование инклюзивного пространства также предполагает и усиление материальной и персональной ответственности менеджеров медицины за деятельность государственной системы социальной поддержки, ведь своевременность, адекватность реальной ситуации и удобство для граждан в процессе предоставления социальных гарантий - прямой результат деятельности управленца медицинским учреждением (Борщева, 2014).

Деятельность в области своевременной профилактики социально-значимых заболеваний также является важной составляющей деятельности менеджмента здравоохранения, поскольку мировой тенденцией является рост заболеваний, приводящих к частичной или полной нетрудоспособности. Защита и помощь людям с ограниченными возможностями - это долг государства и каждого гражданина. В последние годы в Казахстане «оживились» и наука, и общественное сознание в отношении социальной адаптации инвалидов. Безусловно, инвалиды являются самой уязвимой категорией в системе социального обслуживания населения Казахстана. Например, 
Научные труды Московского гуманитарного университета 2018 № 5

пальму первенства после несчастных случаев и катастроф, по частоте случаев, влекущих за собой инвалидизацию, являются такие заболевания как сахарный диабет, онкологические заболевания, заболевания сердечнососудистой системы и опорно-двигательного аппарата, причем медики отмечают, что многие заболевания стремительно «молодеют». К сожалению, эта общемировая тенденция, которая не обошла стороной ни Республику Казахстан, ни Российскую Федерацию. Следующая мировая угроза - число генетически обусловленных врожденных заболеваний и пороки внутриутробного развития, которые обуславливаются ухудшением экологии, но и вместе с тем - несвоевременно выявленными патологическими состояниями будущих родителей. Безусловно, увеличение медицинских рисков требует существенных расходов со стороны государства, но результаты того стоят, ведь многие заболевания при наличии соответствующего технического, методического и кадрового обеспечения не только успешно корректируются, но и нивелируются (Тоцкая, 2014).

В данной ситуации, на менеджмент здравоохранения возложена тяжелая, но выполнимая задача по рациональному распределению и освоению бюджетных средств, там, где это действительно необходимо. Кроме того, от эффективности и своевременности управленческих решений сегодня зависит доверие населения к оказываемым медицинским услугам, а значит и желание обращаться в медицинские учреждения для ранней диагностики и лечения. Поэтому, менеджмент здравоохранения на современном этапе получил существенный законодательно-правовой импульс развития, на фоне антикоррпуционной борьбы и политики управления кадровыми резервами для государственной службы. Сегодня государственная политика нацелена на создание четкого механизма управления здравоохранением, результативность которого оправдывает затраты на его развитие. Искоренение таких негативных проявлений как коррупция, бюрократия, халатность и отстраненность управленцев от деятельности медицинского учреждения являются базовыми принципами, которые способны обеспечить не просто удовлетворенность населения медицинскими услугами, но и сторицей окупить текущие вложения государства в сферу здравоохранения (Михайлова, 2015: Электр. ресурс).

К общеизвестному выражению, что «болезнь легче предотвратить, чем лечить», можно лишь добавить, что лечить последствия - еще и невероятно дорого, а порой и безрезультатно.

Каковы же инновационные возможности для использования менеджмента здравоохранения в решении озвученной проблемы? В первую очередь, важным является обеспечить технологическое и методологическое основание для функционирования системы менеджмента здравоохранения 
как открытой системы. На данный момент приоритетным условием является возможность взаимодействия с администрацией медицинских учреждений для решения вопросов обслуживания, упрощение доступа к медицинским услугам, находящимся в прямой компетенции менеджеров здравоохранения. В числе таких услуг - прохождение медэкспертизы, постановки на учет, сбора и подачи документации, получения консультационных услуг касательно организационных и правовых вопросов обеспечения медицинских и услуг и социальных гарантий, рассмотрения жалоб со стороны населения и координация мер по их устранению в случае необходимости.

А между тем, не всегда менеджеры медицинских учреждений наряду с исключительным положением в коллективе понимают и исключительную ответственность за непосредственный результат его работы. Сегодня персонификация ответственности является общемировым трендом менеджмента в целом и медицинский менеджмент для дальнейшего инновационного развития должен идти в ногу со временем. Без персонификации ответственности осуществить качественный и целенаправленный скачок в сторону инновационного развития системы здравоохранения попросту невозможно.

В первую очередь, для персонификации ответственности необходимо использовать современные коммуникационные и информационные технологии, которые делают возможным и построение открытой и прозрачной системы менеджмента здравоохранения, как для медицинских коллективов, так и для населения. Сегодня, технически возможно осуществлять связь и контроль над процессом обслуживания населения, работать над определенными вопросами в любое время и вне зависимости от расстояний.

Однако, слабое использование коммуникационных технологий в менеджменте здравоохранение и наличие бюрократических препон зачастую вынуждает население по насущным вопросам обращаться напрямую в Министерство здравоохранения. Тем не менее, большинство вопросов можно и нужно решать на местах, для чего имеются и большие технические и информационные возможности. Менеджмент здравоохранения должен стать действительно открытой системой, для постоянного взаимодействия с населением и включенным в текущие проблемы медицинских организаций, тогда и затраты на его развитие будут обусловлены объективной необходимостью. Министерство здравоохранения должно решать задачи более широкого формата, и иметь возможности полагаться на аппарат управленцев на местах.

Кроме того, открытость непосредственного руководства медицинских организаций создает благоприятные условия для повышения доверия и удовлетворенности населения оказываемыми услугами, исключает излишнюю конфликтность и способствует формированию отлаженного механиз- 
ма работы с гражданами.

Информационные технологии, такие как средства удаленной связи, информационные ресурсы должны быть использованы в качестве средств связи, повышающих качество оказываемых населению медицинских услуг. Причем речь идет об общедоступных средствах, а не космических технологиях. Например, доступная и открытая информации о контактах менеджера медицинского учреждения в таких системах как Wats'ap, Twiter и т.п. Дает возможность населению не только решать вопросы на местах, но и повысить контроль над деятельностью администрации медицинской организации в области работы с населением, Функции записи разговора и средства видеонаблюдения, также способствуют открытости и прозрачности системы менеджмента здравоохранения. В то же время, для компетентного и эффективного сотрудника, современные средства связи и оперативного наблюдения также являются своего рода защитой от необоснованных жалоб и незаконных действий со стороны пациентов и коллег, что позволяет снизить уровень стресса и работать строго в рамках полномочий и законности, без оглядки на потенциально возможное давление.

Кроме того, инновационное развитие предполагает и использование научно-методологических достижений современного менеджмента применительно к сфере медицины. Сегодня невозможно решать новые задачи старыми способами: крайне сложно строить современную модель здравоохранения, качественно соответствующую потребностям общества XXI века, опираясь на устаревшие принципы и стили руководства. Современный руководитель медицинского учреждения должен уметь соотносить свои личные качества и профессиональные для максимального развития потенциала медицинского учреждения (Козак, 2016: 412).

Подводя итог, стоит отметить, что ведущим принципом деятельности системы менеджмента здравоохранения сегодня становится не исполнение плана по документообороту, и не формирование экономических показателей, а социальный эффект. При этом все прочие аспекты - финансовый, материальный, научный и кадровый все больше рассматриваются не как цель, а средства достижения цели, требующие рачительного и взвешенного использования. Поэтому, менеджмент здравоохранения в условиях инновационного развития должен быть ориентирован, прежде всего,на теметоды, средства и возможности, внедрение которых способно обеспечить социально-значимый эффект.

\section{СПИСОК ЛИТЕРАТУРЫ}

Государственная Программа развития здравоохранения Республики Казахстан Денсаулық на 2016-2019 гг. [Электронный ресурс] // Официаль- 
ный интернет-ресурс Министерства руда и социальной защиты населения Республики Казахстан. URL: https://www.enbek.gov.kz/ru/node/332663 (дата обращения: 05.08.2018).

Распоряжение Правительства РФ №1662-р, (в ред.10.02.2017) «0 Концепции долгосрочного социально-экономического развития Российской Федерации на период до 2020 года» [Электронный ресурс] // Правительство Российской Федерации. URL: http://government.ru/info/6217/ (дата обращения: 05.08.2018).

Конституция Республики Казахстан от 30 августа 1995 года, с изменениями и дополнения по состоянию от 10.03.2017 [Электронный ресурс] // Параграф. Информационные системы. URL: https://online.zakon.kz/ Document/?doc_id=1005029 (дата обращения: 05.08.2018).

Конституция Российской Федерации от 12 декабря 1993 года, с учетом поправок от 21.07.2017 №11-ФКЗ [Электронный ресурс] // Консультант. URL: http://www.consultant.ru/document/cons_doc_LAW_28399/ (дата обращения: 05.08.2018).

Общая численность инвалидов по группам инвалидности в РФ/Федеральная служба государственной статистики [Электронный ресурс] // Федеральная служба государственной статистики PФ. URL: http://www. gks.ru/wps/wcm/connect/rosstat_main/rosstat/ru/statistics/population/ disabilities/\#, (дата обращения: 05.08.2018).

Численность зарегистрированных инвалидов в разрезе регионов/Министерство Национальной экономики Республики Казахстан. Комитет по статистике инвалидов [Электронный ресурс] // Министерство национальной экономики Республики Казахстан. URL: http://stat.gov.kz/faces/wcnav_ externalId/homeNumbersSocialPolicy;jsessionid=4tHEHQOX3wNPlikCnpt9v qtiQ1MoutGg_6W1 mm4Tgcmbhklu1qB!-1634420636!2114979756?lang=ru\&_ afrLoop=237138970905734\#\%40\%3F_afrLoop\%3D237138970905734\%26lan g\%3Dru\%26_adf.ctrl-state\%3Dsg355t4bt_4 (дата обращения: 05.08.2018).

Приказ Минобрнауки РФ от 19 декабря 2014 года «Об утверждении Федерального государственного образовательного стандарта начального общего образования обучающихся с ограниченными возможностями здоровья» [Электронный ресурс] // Министерство образования и науки Российской Федерации. URL: https://минобрнауки.pф//документы/5132 (дата обращения: 05.08.2018).

Борщёва, Н. Л. (2014) Проблемы развития инновационной деятельности в здравоохранении // Экономика и менеджмент инновационных технологий. № 1. С. 12-16.

Добрусина, М. Е. (2016) Медицинский менеджмент: формирование профессиональных компетенций // Стратегия бизнеса. № 9 (29). С. 8-11. 
Муханов, А. (2017) Численность трудоустроенных инвалидов в Казахстане преувеличено [Электронный ресурс] // Уральская неделя. URL: http://www.uralskweek.kz/2017/02/09/chislo-trudoustroennyx-invalidov-vkazaxstane-preuvelicheno/ (дата обращения: 05.08.2018).

Махашев, С. (2017) Онлайн сурдопереводчики внедрены в ЦОНах [Электронный ресурс] // Новости Видео. URL: http://newsvideo.su/video/6146377 (дата обращения: 05.08.2018).

Михайлова, А. (2015) Квалифицированный руководитель в области здравоохранения - залог качественной медицинской помощи [Электронный ресурс] // Информационно-правовой портал Гарант.py. URL: http:// www.garant.ru/article/604322/ (дата обращения: 05.08.2018).

Козак, Н. Н. (2016) Стили управления и этика топ-менеджера. М. : Библиотека топ-менеджера. 412 с.

Тоцкая, Е. Г. (2014) Управление инновационной деятельностью в здравоохранении на региональном уровне // Бюллетень сибирской медицины.№ 2. С. 27-29.

Дата поступления: 15.09.2018 2.

Мураталиева Акмарал Асильбековна - магистрант 2-го курса специальности «Государственное и муниципальное управление» кафедры менеджмента Московского гуманитарного университета. Адрес: 111395, Россия, г. Москва, ул. Юности, д. 5. Тел.: +7 (747) 667-75-10. Эл. адрес: akmaral.12_88@ mail.ru. Научный руководитель - д. ф. н., проф. 3. С. Айдарбеков.

Muratalieva Akmaral Asilbekovna, Graduate Student, Department of Management, Moscow University for the Humanities. Postal address: 5, Yunosti St., Moscow, Russian Federation, 111395. Tel.: +7 (747) 667-75-10. E-mail: akmaral.12_88@mail.ru. Scientific Adviser-Z. S. Aydarbekov, Doctor of Philosophy, Professor.

\section{Для цитирования:}

Мураталиева А. А. Инновации и современные тренды в менеджменте здравоохранения Республике Казахстан и Российской Федерации [Электронный ресурс] // Научные труды Московского гуманитарного университета. 2018. № 5. URL: http://journals.mosgu.ru/trudy/article/view/829 (дата обращения: дд.мм.гг.). DOI: 10.17805/trudy.2018.5.9 